\title{
Alternate Bearing in Olive - A Review
}

\section{Darpreet Kour*, Parshant Bakshi, V.K. Wali, Nirmal Sharma, Arti Sharma and Mudasir Iqbal}

\author{
Division of fruit Science, Faculty of Agriculture, Sher- $e$ - Kashmir University of Agricultural \\ Sciences and Technology of Jammu, Chatha, Jammu, 180009, India
}

*Corresponding author

\section{Keywords \\ Olive, Alternate bearing, Endogenous Hormonal content, Alternate bearing reduction}

\section{Article Info}

Accepted:

16 August 2018 Available Online: 10 September 2018

\section{A B S T R A C T}

Alternate bearing is a wide spread phenomenon in many fruit tree species and cause severe labour, marketing and economical problem. The term "alternate or biennial" bearing designate the production of a heavy fruit crop "On" year followed by a light fruit crop or trees may not bear a crop at all the next "Off" year. Alternate bearing is a widespread problem for growers of fruit trees, occurring in both evergreen and deciduous trees. It is more pronounced in old productive trees (more than 10 years) in comparison with the young productive trees (about 3-5 years). The domestic olive (Olea europaea) is genetically high alternating in fruit production. The degree of alternate bearing is highly dependent on the environmental conditions and might be very different in accordance with the climate in each growing region. The expression of alternate bearing involves a wide range of changes in activation and repression of endogenous metabolic pathway. The production of olive remains fluctuating over the years due to the problem of alternate bearing and thus the trade and consumption of the producer countries is affected. Horticultural treatments such as thinning, girdling, pruning and irrigation, can reduce the severity of biennial bearing This review article will help understanding the problem, its basic reasons and the possible management practices of the problem.

\section{Introduction}

Alternate bearing of fruit trees has been known since antiquity, and yet it remains a problem with numerous fruit tree crops even today. Still, the metabolic processes, their induction and the messengers involved are only very partially known. There is no doubt, however the processes involved are not universal and rather different in the various fruit tree species (Goldschmidt, 2005).
Although different horticultural practices have been developed and are used to minimise the alternate bearing in many species, their effect is in most cases only partial (Monselise and Goldschmidt, 1982). Alternate bearing has been recognised as one of the most significant constraints facing the olive growers (Rodrigues and Correia, 2009).

The olive tree exhibits a peculiar behaviour, named alternate bearing (biennial bearing or 
periodicity), being defined as a tendency of some fruit trees not to bear a regular and similar crop year after year. Thus, a high-yield crop year ("on-year") is followed by a lowyield or even a no-crop year ("off-year"), which severely affects the fruit yield (Lavee, 2007). In non- irrigated olive groves the yield may vary between 7-8 tons/ha and a few hundred $\mathrm{Kg}$. The occurrence and development of alternate bearing is potent also in intensive orchards with controlled irrigation, nutrition and training techniques, though the level of fruit production is higher and better controlled (Lavee, 1989). Without specific intervention, the gap between 'off' and 'on' years may vary between 5-30 tons/ha (Lavee, 2007). The fructification habits of olive, with the apparent overlap of two consecutive production cycles, may have a significant role in biennial bearing.

In olive trees we observe two growth flushes, the first one in spring and the second in autumn (October), under adequate soil moisture and temperature. Significant genotype variation was reported concerning cultivars, with respect to alternate bearing. The main causal factor of alternate bearing is the inhibition of flower bud induction by the seed of growing fruits, and this is due to competition for nutrients. Under non- irrigated conditions yield during off- years may fall to zero and often the yield is low that growers find it economic to harvest the small crops (Lavee et al., 1983). When we consider alternation of bearing, which is proverbially marked in olive trees, competition between vegetative and reproductive organs would cause reduced production of new branches during the on- year (competition with the growing fruits during summer), producing a smaller number of flowers. The strong growth in the off- year again allows large amounts of flowers to be initiated the next year. Regular cropping, desired but rarely obtained, would occur when a delicate balance between fully vegetative and reproductive branches is attained, quantitatively and qualitatively influenced by interaction of sinks as well as climatic factors.

The phenomenon is largely determined by flowering load (Cuevas et al., 1994) and it is a feature to a greater or lesser extent of all cultivated olive varieties. And can be limited to an individual olive tree in an orchard or even of individual parts of a single tree (Davis, 1957). However, the costs of fertilizers, pesticides, pruning, irrigation and harvest are almost constant for a certain level of management and almost independent of crop load, which significantly reduced the profit in the off year. The two main factors that can reduce the intensity of alternate bearings are pruning and productivity. Furthermore, the irrigation schedule may reduce alternate bearing. Mineral nutrition is also a determining factor. Nutrient deficiency, especially of $\mathrm{N}$ during the period of flower bud differentiation, affects vegetative vigour, the size of fruits and flowering of the following spring (Fernandez- Escobar et al., 1999, 2004). Horticultural treatments such as thinning, girdling, pruning and irrigation, can reduce the severity of biennial bearing. According to Levin and Lavee (2005) alternate bearing is still a serious problem in the cultivation of numerous fruit species, including olives, which consequently must be managed in order to minimise the adverse effects on production (Tapia et al., 2006). The objective of this article is to present the main endogenous and environmental factors that lead to alternate bearing and to review approaches with which alternate bearing is reduced.

\section{Factors responsible for alternate bearing in olive}

The main factors responsible for alternate bearing: flower-site limitation, endogenous 
plant growth hormones and carbohydrate storage.

\section{External factor}

\section{Environmental factor}

Environmental factors during winter have a role in flower induction and subsequent initiation. Flower initiation of olives occurs as early as November, well before significant chilling has occurred. The role of winter chilling needs re-evaluation; are low temperatures necessary for induction and initiation, or just for breaking dormancy of buds. Cultural and environmental factors, such as pruning, drought, inadequate chilling and light intensity, may influence flower bud formation and contribute to alternate- bearing.

\section{Temperature}

Alternate bearing is typically initiated by adverse climate. Once initiated, in the absence of additional environmental constraints affecting crop load, the bearing status of an orchard alternates between 'On' and 'Off' years, with 'On' years exhibiting less vegetative growth than 'Off' years. This biennial cycle, however, can be reset by adverse environmental conditions affecting bloom and fruit set. Adverse conditions 8-10 weeks prior to bloom may cause abortion of female flower parts, in high proportion of staminate (male) flowers that do not give rise to fruit. Additionally, adverse weather conditions, resulting in loss of crop during an anticipated "On" year may render the season an "Off" year. Temperature constrains could be the main climatic effect that could affect flowering. Regulation of flowering by temperature has been widely studied in olive tree (Malik and Bradford, 2009). Temperature is the major environmental factor influencing the process leading to flower differentiation. The requirement of adequate amounts of winter chilling (below $9^{\circ} \mathrm{C}$ ) for flower bud differentiation was suggested many years ago. The winter chilling is required to release predetermined flower buds from a dormant phase enabling the inflorescences development for a forthcoming yield (Rallo and Martin, 1991; Rallo et al., 1994). Unfavourable temperature regimes particularly in the winter are instrumental in inducing alternate bearing in general and orchard or regional synchronized one in particular. In regions with uniformity cool winter temperatures, the potential for flower buds to differentiate in trees is high. Small differences in vegetative growth of fruit production between years will gradually lead to alternate bearing development with an individual schedule for each tree. High temperatures and dry winds on the one hand and heavy rain or frost on the other might lead to a fruitless, highly vegetative season, which in turn will result in over- cropping during the following year.

Moreover, fertilization success is very sensitive to extreme temperature since it inhibits pollen germination and slow down or stop the pollen tube. The receptivity of the stigma can also be shortened by dry winds and hot environmental conditions.

\section{Low air humidity}

This factor affects yield through an excessive drop of fruits of olives. Low air humidity may also be connected with cool night temperatures in arid zones. Low air humidity and other environmental stresses may also have indirect effects on set by enhancing leaf senescence and causing premature drop (Addicott and Lyon, 1973).

\section{Edaphic stresses}

Little is known about effects of soil texture, water penetration, aeration, and salinity on alternate bearing, although conditions 
conducive to root activity are detrimental to yields. Saline conditions cause leaf drop and are a possible indirect cause to the reduction of available reserve. During flower formation in olives, soil moisture stress is conducive to leaf abscission and to a high percentage of sterile flowers. Stressed olive tress had only $47 \%$ flowers per inflorescence, $22 \%$ perfect flowers, and $9 \%$ fruits as compared with unstressed controls (Hartmann and Panetsos, 1961).

\section{Water stress}

Water stress at any stage may induce a misbalance between vegetative development and fruiting, which could result in initiation of alternate bearing. Drought may have an effect on alternation through enhanced drop of reproductive organs and leaves and reduced vegetative growth. Any extreme conditions leading a water or thermal stress at any stage during the growth cycle of the tree may induce a misbalance between vegetative development and fruiting, which could results in an initiation of alternate bearing.

\section{Internal factor}

\section{Endogenous plant growth hormones}

\section{Gibberellins}

A lack of flower bud formation during the "on" year is a common characteristic of most alternate-bearing species. Ulger et al., 2004 reported that some growth hormones like the abscisic acid (ABA), gibberellins like gibberellic acid $\left(\mathrm{GA}_{3}\right)$ and auxins like indole2- acetic acid (IAA) have important roles on the alternate bearing. Gibberellins (GAs), which are produced in great abundance by the seed during its development, produce an inhibiting effect on the floral induction. Many studies show the involvement of GAs in the control of olive plant flowering and also show that the pit hardening phase has a physiological importance in the floral induction (Stutte and Martin, 1986; Navarro et al., 1990; Rapoport et al., 1990; FeernandezEscobar et al., 1992; Lavee and Haskal, 1993; Proietti and Tombesi, 1996). Ferguson et al., 1994 reported that phytohormones have a triggering effect on the initiation of vegetative and flower buds on the new shoot growth of olives. GAs has a high degree of hydroxylation. Hydroxylation is necessary for the movement of GAs in the tissue where fruit bud induction occur. Pharis and King (1985) reported that the negative effect performed by GAs produced by the developing seed on the flower buds strongly depends on their qualitative feature, on the duration of their movement within the plant, and on the metabolic speed with which more or less active products are found.

The olive tree has a natural tendency to produce high number of flowers and fruits. Yet, the developing seeds inside the fruits produce molecular messengers (like the gibberellins) that inhibit the floral induction, arresting the buds and directing them towards shoots and leaves (vegetative buds). GA levels started to rise at fruit set and these levels were maintained until harvest in the "On" year.

\section{ABA}

Zeevaart (1978) reported that ABA plays a role in flower induction in several plant species. The levels of free ABA in the lateral buds (potential floral buds) of trees in the "Off"-year showed a sharp and significant increase from September until October as compared to the "On"- year for the respective period (stage of floral development).

The tree in the "Off"- year produce more ABA (promotive to floral induction and initiation) than trees in the "On" year (Saleh and Mostafa, 2008). 


\section{IAA}

Concentration of IAA in the olive lateral buds in the "On"- year show a significant increase during November and December as compared to that in the "Off"- year tress for the respective period. While in the following year, IAA concentrations in the "Off'- year and in the "On"- year trees were almost at the same level throughout September- March. However, during the end dormancy period (January), level of IAA did not show dramatic changes in the lateral buds and the levels remained almost steady (Saleh and Mostafa, 2008).

\section{Cytokinins}

Cytokinins concentration in the lateral buds of "On" year olive trees were significantly higher than that in the "Off" -year trees throughout the period September to April. Kinetin- like cytokinin levels in leaves, nodes and shoot tips in the "On" year were higher than in the "off" year. Shulman and Lavee (1976) showed that compared to most other fruits cytokinins in olive fruit increases with maturation. However, these levels in winter, spring, and summer were not statically significant, while the levels were different in fall. Kinetin- like cytokinin in November and December in the "On " year produced detectable peaks.

High concentration of phytoharmones, especially $\mathrm{GA}_{3}$-like substances during the initiation period, promoted vegetative bud formation, while lower concentration favoured flower bud formation during the fall initiation period.GA- like substances and IAA concentration were found to be higher in the "Off' year, while levels of kinetin-like substances were found to be essentially the same in both "on" and "off' years during bloom (May). Low levels of GA- like and high levels of ABA were associated with blooming and fruit setting. Ferguson et al., (1994) studied that phytoharmones have a triggering effect on the initiation of vegetative and flower buds on the new shoot growth of olives. Levels of endogenous phytoharmones in July, November, January, and March were found to be critical for flower bud induction and development. If endogenous hormone levels are high during these months, vegetative bud formation is induced, while low levels promote flower bud formation.

\section{Carbohydrates}

The growing of a large number of fruits may produce the depletion of the carbohydrate reserves in the tree. Additionally the stored carbohydrate amounts in plants differ in the on- and off- years, and consequently, an association between carbohydrate metabolization and biennial bearing was reported (Barranco et al., 2010). The floral bud inhibition may occur when the olive tree carbohydrate reserve are scare, which is typical after a high- yield fruit production. Gold smith (2005) proposed thee principal regulatory mechanism involved in the induction of alternate bearing: hormonal control, nutritional (carbon and mineral balance control and flowering site limitation. Fluctuation in tree's carbohydrate $(\mathrm{CHO})$ budget is often suggested as a key factor triggering alternate bearing (Monselise and Goldschmidt, 1982; Oliveria and Priestley, 1988).

Most tree species accumulate $\mathrm{CHO}$ reserves, supporting future metabolic needs occurring within as well as between annual cycles (Kozlowski, 1992). The reliance of the reproductive phase on the previous year's reserve was reported to be a matter of timing: fruit number of fruit growth and development might be restricted due to depleting reserve prior to maturation of the new vegetative growth (Berman and DeJong, 2003; Wunsche and Ferguson, 2005; Span et al., 2008. and Marra et al., 2009). 
The growing of a large number of fruits may produce the depletion of the carbohydrate reserves in the tree. Fluctuation in tree's carbohydrate $(\mathrm{CHO})$ budget is often suggested as a key factor triggering alternate bearing. A large crop in a year depresses tree reserve. It is widely accepted that biennial bearing is mainly regulated by the competition for resources between shoots and fruits which develop simultaneously. The sink capacity of a high number of fruits limits the vegetative growth, reducing the length of the new shoots.

The reduction in the number of nodes and in leaf area reduces, respectively, the potential sites for flower initiation and the source size for the next season (Rallo and Suarez, 1989). The inflorescence behaves as a unit of fruitfulness, where the competition for reserves among the developing fruits seems to be the main factor in regulating final crop (Cuevas et al., 1995). Thus the higher crop in the preceding year depletion of tree reserves and smaller the next crop.

\section{Nutritional factor}

Nutritional deficiencies might enhance alternate bearing. Adequate $\mathrm{N}$ is necessary for good bloom, fruit set, and yield. Nitrogen was stored in new leaves and stems, and also in old stems, during the off year, and appeared to be mobilized from these tissues during the 'On' year to support new growth. Leaf $K$ concentration was significantly higher in the current- season leaves of both, the 'Off' and 'On' year, than in the one year old leaves. Potassium concentration of current season leaves gradually decreased from the beginning of the season to August, and remained at approximately these values during the autumn. Leaf $\mathrm{K}$ concentration declines in most tree crops as the season progresses (Ryugo, 1988). In olive, this decline was particularly marked. The high leaf $\mathrm{K}$ accumulation following the 'off' year and the rapid decline after March of the 'on' year suggests a large demand by the reproductive structures of the olive.

\section{Crop load}

The heavy crop load produced during the onyear is perhaps the most universally recognized cause of alternation. Fruit load is one of the main cause-and-effect factors in the phenomenon of biennial bearing, often disrupting the balance between reproductive and vegetative processes. The inhibition of floral induction by seeded developing fruits is the major factor in the olive's biennial behaviour. Alternate bearing in olive is largely determined by flowering load. Heavy flowering in one year is followed, the next year, by very few flowers or none at all. The trees with lightest flower load had greater ovule longevity than tree with the heaviest flower load. The seeds of the high fruit population developing during the summer of the "On" year inhibit flower induction for the next "off' year (Fernandez- Escobar et al., 1992).

\section{Competition between vegetative and reproductive sinks}

Seeds in growing fruit lets are usually considered a powerful sink favouring better mobilization of photosynthetic products by the growing fruit. There are conditions, however, when a new vegetative flush may become better sinks than fruits. It has been reported that a delicate balance between fully vegetative and reproductive branches is needed for the regular cropping of olives. Due to the complexity and the overlapping of vegetative growth and reproduction inside shoot cycle and among the other over- cycles, alternate bearing is observable at different ranks among shoots in the same branch, branches in the same tree, trees in same orchard and areas in the same district (Lodolini, 2005). As a consequence alternate 
bearing is more severe where adverse environmental conditions are frequent (Lodolini and Neri, 2012).

\section{Flower bud induction}

The effect of fruit on the level of vegetative growth, the developing fruits were shown to have a significant effect on the development of flower. For various fruit species it was suggested that the developing fruit is a strong sink competing for metabolites with the vegetative growth. Some workers found a correlation between 'On' and 'Off' year with primer metabolites, such as carbohydrates (Seyyednejad et al., 2001) and polyamines (Pritsa and Voyiatzis, 2004). It can be concluded that the effect of the developing fruits on reducing flower bud differentiation for the following season is of regulatory nature via signals produced by the developing embryos. A significant change in the content of secondary metabolites, such as chlorogenic acid in the leaves of olive trees between 'on' and 'off' year. It is assumed that the signal inducing the synthesis and accumulation of these phenolics metabolites in the leaves is initiated in the developing embryos in the fruits. Injection of chlorogenic acid during the winter before an 'On' year into the xylem of trees in the field reduced flower bud differentiation on the treated scaffolds by more than $50 \%$. It could be concluded therefore that the developing fruits in the present year are not only in competition with the vegetative growth but also have a direct effect on the metabolism leading to reproductive induction and differentiation of the buds for the potential yield in the following year.

\section{Protein content}

The total extractable protein content in the leaves of "off' trees was considered lower than in the leaves of 'On' trees (Lavee and Avidan,
1994). In the bark an opposite relation was found this was observes in the cultivars 'Koroneki', 'Uovo de piccione', 'Manzanillo' and 'Barnea'. The least difference was recorded in the leaves of 'Koroneiki', which demonstrates the least alternate capacity. In most cases proteins of 28 and $32 \mathrm{kD}$ were present in samples of the off year leaves, and 22 and $14 \mathrm{kD}$ were in higher concentration in the leaves of the "On" tree. The bark of one year old shoots undergoing metabolic change with the transfer from 'on" to "off" phase. At the pre bloom stage the protein level was considerable higher in the leaves of the 'On' trees.

\section{Amino acids}

The Physiological maturity of the shoot has been considered to have relation with the flowering behaviour of the crop. Amino acids act like messengers evoking the process of floral initiation by increasing availability of essential metabolites at the growing apices of fruit trees (Proietti and Tombesi, 1996).

During 'Off' year a gradual, but significant increase in endogenous levels of asparagines, glutamine and tryptophan was observed from October to May. A more or less similar trend of asparagines, glutamine and tryptophan was observed during "On" year. The comparatively lower levels of amino acids during autumn and winter season might be ascribed partly too restricted uptake of $\mathrm{N}$ from soil due to acute water stress and partly to their faster utilization for biosynthesis of mono and polyphenols and soluble proteins in the plant system, and consequently their endogenous levels have registered a decline.

The increased translocation of these amino acids from bark to growing apices of the tree including flower buds might be one of the reasons responsible for causing an upsurge in their endogenous level. 


\section{Phenolic}

The phenolic compounds in plant leaves are known to be involved in several physiological mechanisms. It is believed that initial signal for alternate bearing may be received by the leaves in olive (Ryan et al., 2003). The chemical changes in the leaves include phenolic and flavanolic compounds, which arrest flower bud formation during the physiological initiation period. Phenolics act as uv- protecting agents in plant tissues (Mert et al., 2013) and are often involved in plantpathogen interactions, both constitutively and as newly induced compounds.

\section{Mitigation of alternate bearing}

\section{Pruning}

Pruning is necessary to adjust the trees to the climatic conditions of the area and increase plantation's productivity. Olive trees can be prunes in spring or summer. Rugini and Pannelli, 1993 reported that severe pruning was effective to enhance the fruit- set of the olive cultivar 'Frantoio'. They also reported that hexaconazole treatment as a candidate practice to increase fruit set in a sustainable way. The action of this substance on plants may be considered like a "Chemical pruning" modifying the distribution of carbohydrates between shoot elongation and flower differentiation (Gomathinayagam et al., 2007).

\section{Aim of pruning}

To balance vegetation with fruit yield.

To minimize the non-productive period.

To renew the canopy in old, non- productive trees to stimulate productivity (Cimato et al., 1990).

To prolong the productivity of the trees.
To delay senescence.

To save soil water, a critical factor in nonirrigated orchards.

\section{Rules of pruning}

The style of pruning depends on olive tree age, crop load, the use of olives as table or olive oil fruits, soil fertility, environmental conditions and fruit load. Although these factors differ from one area to another and from cultivar to cultivar, certain general rules are applicable to pruning:

It is not necessary to prune olive trees every year: in some cases pruning is conducted every 2 years. Therefore, pruning cost is a very important factor.

Plant age is determining factor of the type of pruning (light, medium, severe).

The pruning method should be simple and fast; we can then check light penetration into the canopy and assess the need for more severe pruning.

Pruning starts from the top of the tree and proceeds towards the base. Larger shoots are cut first, followed by those of smaller diasmeter.

In mature plants pruning is light; pruning intensity increase with age of plant.

The cut should be executed close to the point of attachment of the lateral branch.

\section{Pruning Period}

Pruning of olive trees can be done right after harvest. For table olive varieties, pruning begins in November- December for green olives or February-March for black olives. In general, pruning can be performed from 
autumn to the first months of spring, but it should be delayed in areas with high risk of frosts.

\section{Types of pruning}

\section{Pruning during the early stages of tree growing}

The aim of this type of pruning is to develop a tree shape during the first years of the plantation, in order to facilitate all cultural practices (spraying, soil cultivation, irrigation, harvest etc.) and to best exploit the tree the sunlight and rainfall occur in the area of cultivation. The most shape for the olive tree is the "cup-shaped" tree or "free-cup. To form this shape the newly planted one-year old trees are cut back at a height of approximately 60$80 \mathrm{~cm}$ above soil level. The main focus of such a practice is to force 2-4 side branches to be developed, around the tree axis at a distance of $30-40 \mathrm{~cm}$ from each other and at a height of approximately 40 (the first) till 80 $\mathrm{cm}$ from the ground. These branches should comprise in the future the main (primary limbs) branches of the tree. On these branches new side shoots will be developed by cutting down the old branches at a length of approximately $50 \mathrm{~cm}$, thus removing the so called shoot tip dominance and make the lower buds to sprout. Kumar et al., 2014 reported that moderate severity of pruning (30\% pruning on previous season growth) has been adjudged as optimum level of pruning in improving quality of ber fruits cv. Banarsi Karaka yield.

\section{Pruning for fruiting}

Olive fruit produce fruits in last year's branches. This means that in order for us to have fruits every year we should ensure adequate vegetative growth every year. Very vigorous shoots are not productive, as they are mostly full of vegetative buds. The aim of pruning thus is to induce branches that will bear fruits by exposing them to light and maintain the fruiting zone vigorous and active. The olive tree produces fruits mainly at the periphery of the canopy and at its top. This happens because these parts of the tree are fully exposed to sunlight and become fertile. Based on this fact and the aims analysed above the pruning for fruiting should comprise the removal of any part that shades other younger parts of the trees. When a thick branch is to be cut down we must be very careful in order to avoid tearing of the bark of the remaining branch. The first cut is being made at the down side of the branch till the middle of it, some centimetres away from the point where we want to cut the branch. The second cut is done centimetres away from the first cut and usually before the completion of this cut, due to the weight of the branch; the branch will fall down, tearing the bark of the remaining branch till the point though of the first cut. Then we can easily cut down the small part remained, to the point of the desired cut.

\section{Renovating pruning}

The main characteristic of the olive tree is its longevity, because it has the ability to produce new shoots from nearly every part of the wood, thus making it possible to renovate senescent or frost - fire damaged trees. This type of pruning is comprised by cutting the tree at the main branches or even at its trunk. The most significant practice though is to come back during the next months and remove by hand (when they are still young) the shots that will be of no use to us. We should not wait till the next year in order to give the tree the shape we want (pruning for giving the tree its shape), as it is most likely to have wasted almost one year till the beginning of fruit production. The new tree enters the fruiting period after 3-5 years depending on the cultural practices. 
Critical periods for soil moisture in olive

\begin{tabular}{|l|}
\hline Period \\
\hline August to \\
December \\
\hline December to \\
January \\
\hline Late March \\
to harvest
\end{tabular}

Growth events

1. Flower bud development

2. Bloom

3. Fruit set

4. Shoot growth

Stage 1 of fruit growth due to cell division

Shoot growth

Stage 3 of fruit growth due to enlargement

Shoot growth

\section{Effect of low moisture in soil}

Reduced flower formation

Incomplete flower

Increases alternate bearing

Decreases shoot growth

Small fruit size due to decreased cell division

Fruit shrivel

Decreased shoot growth

Small fruit size due to reduced cell expansion

Fruit shrivel

Decreased shoot growth

Factors which increases or decrease fruit thinning

\section{Increased thinning}

Young trees

Moist weather

High relative humidity

High maximum temperature

Softly sprayed water

Slow drying conditions

High concentration of chemicals

Trees of low vigour

Close spacing of trees

Light pruning

Heavy flowering

Poor pollination

Previous heavy crop

Addition of wetting agents

\section{Decreased thinning}

\section{Mature trees}

Dry weather

Low relative humidity

Temperature lower than maximum

Heavily sprayed water

Fast drying conditions

Low concentration of chemicals

Vigorous trees

Wide planting distances

Severe pruning

Light flowering percentage

Adequate pollination

Previous light crop

No inclusion of wetting agents

Method of establishing NAA Concentration to Use

\begin{tabular}{|l|l|l|l|l|}
\hline Examples & Full bloom & Spray day & $\begin{array}{l}\text { Days after full } \\
\text { bloom }\end{array}$ & $\begin{array}{l}\text { NAA } \\
\text { concentration }\end{array}$ \\
\hline $\mathbf{1}$ & May27 & June 10 & $14 \times 10 \mathrm{ppm}=$ & $140 \mathrm{ppm}$ \\
\hline $\mathbf{2}$ & May29 & June 15 & $17 \times 10 \mathrm{ppm}=$ & $170 \mathrm{ppm}$ \\
\hline $\mathbf{3}$ & May25 & June 7 & $13 \times 10 \mathrm{ppm}=$ & $130 \mathrm{ppm}$ \\
\hline
\end{tabular}


After every pruning or cutting action it is advisable to cover the wounds with wound sealing pastes and to spray the trees with a copper based fungicide product, in order to prevent the tree form bacterial or fungi infections. Pruning of olive trees can be done during the period between autumn and winter.

It is generally performed after harvest but we should wait till the period of heavy rains and frost has passed, in order to prevent infections. We should never perform pruning during a rainy day, as this will probably spread bacteria to the cutting surfaces or inside wounds not seeing by bear eye, resulting in bacterial canker of the olive tree (for those varieties susceptible to bacterial canker).

\section{Irrigation}

The alternate bearing of the olive tree is caused because the heavy crop suppresses shoot growth and exhaust food reserves. This results in reduced flowering and fruit set in the following year. Irrigation allows avoidance of conditions of stress that would otherwise cause reduced olive oil accumulation in fruits (Fernandez and Moreno, 1999). It also increases yields is an augmented capacity for quantity of fruit per tree (Gucci et al., 2007). It has been shown that irrigation application during the year can overcome the effect of alternate bearing. Irrigation period early in the growing season enhances shoot growth, which in turn increases the number of fruits in the subsequent season.

In general three irrigation should be applied -

Before flowering- To minimize the extent of premature pistil abortion.

At the time of fruit set- To avoid excess fruit drop.
At the time of maturity- To reduce the preharvest fruit drop.

\section{Thinning}

It is the removal of some plants or parts of plants to make room for the growth of others. Thinning is one of the techniques used to diminish or overcome the biennial bearing in olives Dag et al., 2009). Thinning reduces the crop load leading to the availability of more nutrients and assimilates that would increase the flower bud induction and differentiation. Also, reducing 'On' year crop leads to lowering number of seeds which have negative impact on flower bud differentiation (Bakir et al., 2004). Several growth retardants were applied they were gibberellins inhibitors of the trizole group. Their physiological effect was decreasing the biosynthesis of gibberellins which were known to inhibit the floral bud induction and differentiation. Patel et al., 2014 reported that thinning of leaf to fruit ratio (LFR) of 30: 1 was found most effective to reduce the crop load and improved the physico-chemical characteristics in peach cv. Flordasun.

\section{Aim of thinning}

Reducing limb breakage.

Larger fruit.

Higher- quality fruit.

More consistent yearly crop.

Early maturity.

Lower harvest cost.

\section{Thinning period - May}

\section{Leaf: Fruit ratio and assimilate transport}

Thinning modifies the leaf: fruit ratio; therefore, it reduces fruit competition in olive. A change in the leaf: fruit ratio causes significant differences in fruit growth. Under high levels of assimilate availability in fruits, 
as happens following fruit thinning, the fruit weight increases. The nutrients for olive fruit growth and development are supplied mainly by the leaves of the same shoot. Therefore, in shaded areas where carbohydrate availability is low, olive fruits cannot obtain optimum size although the availability for the whole tree may be high. Fruit thinning increases carbohydrate availability to remaining fruits and results in an increase in size.

\section{Thinning Methods}

\section{Manual thinning}

Manual thinning by removing $50 \%$ of the fruit set prior to pit hardening i.e. first week of June was the most effective treatment in increasing flowering density, sex ratio setting and yield. Due to reducing the number of fruits in the 'on' year which lead to increasing stored nutrients and assimilates and this would result in more flowering and thereby more fruiting in the expected "Off" year.

Fruit removal scheduled until the middle of the summer, which brings about significant vegetative growth, bloom and fruit yield in the subsequent year (Dag et al., 2010.

\section{Mechanical thinning}

Mechanical thinning can be performed by the following methods:

Use of a hand- operated spray, with highpressure water.

Use of mechanical shaker to shake the tree trunk. This method needs skill to avoid overthinning. Furthermore, with this method the larger olives are removed since these fruits obtain a greater directional momentum than small ones. Also, fruits from the stronger branches are removed more easily. Therefore, with mechanical thinning it is difficult to achieve the degree of thinning the grower needs.

\section{Chemical thinning}

NAA, 1- napthaleneacetamide (NAAm) and ethephon- releasing ethylene have been tested for thinning table olives. Chemical thinning has certain advantages over hand- or mechanical thinning:

Low thinning cost.

Greater size of olives, earlier maturation and better quality.

Decrease in biennial bearing.

\section{Thinning with NAA}

While fruit thinning using NAA shortly after full bloom is commonly practiced to increase fruit size in table olives. The ability of that common naphthalene acetic acid (NAA) treatment $(100 \mathrm{mg} / \mathrm{L}, 10$ days after full bloom) to alleviate biennial bearing (Dag et al., 2009). The plant growth regulator Naphthalene acetic acid (NAA) absorbs into the leaves and fruit of the olive tree and is translocated to the fruit stems. An abscission layer forms during the first two weeks after NAA application, causing some fruit to drop.

\section{Girdling}

Also called as ring barking is the complete removal of a strip of bark from around the entire circumference of either a branch or trunk of woody plants. Girdling is considered an important practice responsible for improving fruit setting, yield as well as physical and chemical properties of fruit in various olive cvs. Through accumulation of organic foods and natural hormones above rings. Girdling increases total soluble sugars and starch content in the leaves and shoot 
bark above the girdle during the off year. The optimum time for girdling is from December to February prior to the fruit bud differentiation period. Girdle affects carbohydrate- related gene expression. sFor girdling 2-3 mm wide bark at the base of the branch from all the around was removed without injuring the wood with sharp knife.

\section{Aim of girdling}

Improves fruit setting and yield.

Increase TSS and starch content in the leaves and shoot bark above the girdle.

A combination of Girdling and $\mathrm{Ga}_{3}(50 \mathrm{ppm})$ improves fruit set per panicle in cultivar Gemlik.

\section{Time for girdling: December - February}

\section{Fertilization}

Substantial amounts of nutrients are lost from olive trees as a result of fruit removal, annual pruning of leaves and wood, and natural leaf drop. Appropriate fertilization is necessary to supply the minerals for new growth and for the following year's yield. The balance between NPK fertilizers is useful in the annual growth cycle of olive trees whereas, nitrogen increases leaf chlorophyll levels and photosynthesis, hence promoting shoot growth and flowering. Providing olive trees with additional doses of nitrogen before flowering and fruit set has proved beneficial. It also increases the ability of the olive tree to utilize other nutrients (Stan and David, 2007). Phosphorus is needed for many biochemical processes as cell division, development of meristematic tissue (new growth), photosynthesis linked carbon fixation from carbon dioxide, intermediary metabolism and the utilization of sugars and starch. Potassium has a number of important physiological and biochemical functions including: photosynthesis, respiratory processes, carbohydrate transport, synthesis of nitrogen compounds and carbohydrates, movement of water, and balancing nitrogen fertilizers.

\section{Recommended doses}

All the rates are divided into three doses Applied at January (before flowering) as NPK At June (after fruit set) as NK

At August (after pit hardening stage) as NK.

\section{Spraying of gibberellic acid}

Olive has a very marked alternate bearing pattern (Barone et al., 1994). The role of $\mathrm{GA}_{3}$ in reducing the yield during "On" years may be due to the fact that gibberellins decreased trees blooming in the "On" year and thus reduces competition between flowers and fruits on the nutritional and hormonal contents of the trees and consequently enhances tree production and fruiting in "off" years and reduces alternate bearing. The balance between the amount of developing fruit and the vegetative growth in any given growing season will affect and control the potential fruit production for the following season (Lavee, 2007). Spray olive trees with $\mathrm{GA}_{3}$ before an expected "on" year decreased the percentage of opened flower buds per shoot, number of flowers per inflorescence in the subsequent year.

\section{Effect of fruit removal and seed kill on return bloom}

Fruit removal within 6 weeks of full bloom significantly improved return bloom. Some effect was evident after 9 weeks, but none thereafter. Thus, the presence of fruits inhibits flowering. Also, fruit removal at early stages of fruit development, before endocarp sclerification, promotes flowering the following year. Early fruit removal also 
increased current-year shoot length. Killing the seed at 6 weeks AFB improved return bloom in 'Manzanillo'. Seed-kill treatments were done marginally early, 2 weeks before endocarp sclerifications. Killing the seed also resulted" in early maturity of the fruits, suggesting that absence of seeds or wounding accelerates fruit development.

Alternate bearing is an economic problem for olive growers and industry affecting fruit size and net economic return, causing a price fluctuation between 'on' and 'off' year. It is controlled by an interaction between vegetative growth and fruit load. Environmental conditions are the main trigger to induce over all the metabolic changes leading to alternate bearing expression. Horticultural interventions viz., pruning, thinning, girdling, and other cultural and nutritional means can reduce and even eliminate alternate bearing in regions with favorable and stable climatic conditions.

\section{References}

Addicott, F.T. and Lyons, F.L. 1973. Physiological ecology of abscission. p. 85- 124. In T.T. Kozlowski (ed.) Sheeding of plant parts. Academic Press. New York.

Bakir, I., S. Ulger and D.G. Himelrick. 2004. Relationship of seasonal changes in endogeneous plant hormones and alternate bearing in olive trees, Hort Science, 39: 987- 990.

Barone, E., G. Gullo, R. Zappia and P. Inglese, 1994. Effect of crop load on fruit ripening and Olive oil (Olea europea L.) quality. Journal of Horticultural Science, 69(1): 67-73.

Barranco D, Fernández-Escobar R, Rallo L. 2010. Olive Growing. In 1st English Edition of the 5th revised and enlarged edition of "El Cultivo del Olivo. MundiPrensa - Junta de Andalucía (Madrid,
Spain): Mundi-Prensa - Junta de Andalucía - Australian Olive Association (Rural Industries Research and Development Corporation; RIRDC).

Berman, M.E. and T.M. DeJong. 2003. Seasonal patterns of vegetative growth and competition with reproductive sinks in peach (Prunus persica). Journal of Horticultural Science and Biotechnology, 78:303-309.

Cimato, A., Cantini, C. and Sillari, B. 1990. A method of pruning for the recovery of olive productivity. Acta Horticulture, 286: $251-254$.

Cuevas, J., Rallo, L. and Rapoport, H.F. 1994. Crop load Effects on Floral Quality in olive. Scientia Horticulture 59: 123130.

Cuevas, J., Rapport, H.F. and Rallo, L. 1995. Relationship among reproductive processes and fruitlet abscission in 'Arbequina' olve. Advances in Horticultural Science, 9: 92- 96.

Dag, A., A. Bustan, A. Avni, I. Tzipori, S. Lavee and J. Riov. 2010. Timing of fruit removal affects concurrent vegetative growth and subsequent return bloom and yield in olive (Olea europaea L.). Scientia Horticulture, 123: 469-472.

Dag, A., Butsan, A., Avni, A., Lavee, S., Riov, J. 2009. Fruit thinning using NAA shows potential for reducing biennial bearing of 'Barnea' and 'Picual' oil olive trees. Crop and Pasture Science, 60: 1124- 1130.

Davis, L.D. 1957. Flowering and Alternate Bearing. Journal of American Society of Horticultural Sciences, 70: 545- 556.

Ferguson, L., Sibbett, G.S. and Martin, G.C. 1994. Olive production manual. Agriculture and Natural ResourcesUniversity of California, 3353.

Fernandez- Escobar, R., M. Benlloch, D. Navarro and G.C. Martin. 1992. The time of floral induction in the olive. 
Journal of American Society of Horticultural Sciences, 117: 304- 307.

Fernandez- Escobar, R., Moreno and M. A. Sanchez- Zamora. 2004. Nitrogen dynamics in the olive bearing shoot. Hort Science, 39: 1406- 1411.

Fernandez, J.E. and Moreno, F. 1999. Water use by the olive tree. J Crop Prod 2:101-162.

Goldschmidt, E.E. 2005. Regulatory aspects of alternate bearing in fruit trees. Italus Hortus, 12: 11-17.

Gomathinayagam, M., Jaleel, C.A., Lakshmanan, G.M.A. and Panneerselvam, R. 2007. Changes in carbohydrate metabolism by triazole growth regulators in cassava (Manihot esculenta Crantz); effects on tuber production and quality. Comptes Rendus Biologies, 330: 644-655.

Gucci, R., Lodolni, E., Rapoport, H.F. 2007. Productivity of olive trees with different water status and crop load. Journal of Horticulture Science and Biotechnology, 182: 648-656.

Hartmann, H.T. and C. Panetsos.. 1961. Effects of soil moisture during flower development on fruitfulness in the olive. Proceeding of American Society for Horticultural Sciences, 79:209-217.

Kozlowski, T.T. 1992. Carbohydrate sources and sinks in woody plants. Botanical Review, 58:107-222.

Kumar, H., Katiyar, P.N., Singh, A.K. and Kumar, B.V.R. 2014. Effect of different pruning severity on physicochemical properties of ber (Zizyphus mauritiana Lamk.) cv. Banarasi Karaka. The Ecoscan, 8(3\&4): 203-206.

Lavee S. 2007. Biennial bearing in olive (Olea europaea). Annales Series Historia Naturalis, 17(1): 101-112.

Lavee, S. 1989. Involvement of plant growth regulators and endogeneous growth substances in the control of alternate bearing. Acta Horticulture, 239: 311322.

Lavee, S. and Haskal. 1993. Partial fruiting regulation of olive trees (Olea europaea L.) with Paclobutrazol and Gibberellic acid in the orchard. Advances in Horticultural Sciences, 7: 83- 86.

Lavee, S. and N. Avidan. 1994. Protein content and composition of leaves and bark in relation to alternate bearing of olive trees (Olea europaea L.). Acta Horticulture, 356: 143- 147.

Lavee, S., Haskal, A., and Ben- Tal, Y., 1983. Girdling olive tree, a partial solution to biennial bearing. I. Methods, timing and direct trees response. Journal of Horticultural Sciences, 58: 209- 218.

Levin, A.G., and Lavee, S. 2005. The influence of girdling on flower type, number, inflorescence density, fruit set, and yields in three different olive cultivars (Barnea, Picual, and Souri). Australian Journal of Agricultural Research, 56: 827- 831.

Lodolini, E.M. 2005. Control of fruit production in olive (Olea europaea L.): water, nutrition and orchard aspects. Ph.D. thesis. Politechnics University of Ancona.

Lodolini, E.M. and Neri, D. 2012. How growth and reproduction cycles affect alternate bearing in olive. Acta Horticulture, 949: 191-195.

Malik, N.S.A, Bradford, J.M. 2009. Inhibition of flowering in 'Arbequina' olives from chilling at lower temperatures. Journal of Food Agriculture and Environment, 7: 429-431.

Marra, F.P., E. Barone, M. La Mantia and T. Caruso. 2009. Toward the definition of a carbon budget model: seasonal variation and temperature effect on respiration rate of vegetative and reproductive organs of pistachio trees (Pistacia vera). Tree Physiology, 29:1095-1103 
Mert, C., Barut, E. and Ipek, A. 2013. Quantitative seasonal changes in the leaf phenolic content related to the alternate bearing patterns of olive (Olea europaea L.) cv. Gemlik. Journal of Agricultural Sciences and Technology, 15: 995- 1006.

Moselise, P.S. Goldschmidt, E.E. 1982. Alternate bearing in fruit trees. Horticultural Review, 4: 128- 173.

Navarro, C., Fernandez-Escobar, R. and Benlloch, M. 1990. Flower bud induction in "Manzanillo" olive. Acta Horticulture, 286: 195-198.

Oliveira, C.M. and C.E. Priestley.1988. Carbohydrate reserves in deciduous fruit trees. Horticultural Review, 10: 403-430.

Patel, R.K., Meitel, S.B., Kumar, A., Srivastava, K., Deka, B.C., Deshmukh, N.A. and Verma, V.K. 2014. Effect of leaf and fruit thinning on yield and quality of peach cv. Flordasun, The Ecoscan, 6: 467-471.

Pharis, R.P. and King, R.W. 1985. Gibberellins and reproductive development in seed plants. Annals Review of Plant Physiology, 36: 517568.

Prista, T.S. and Voyiatzis, D.G. 2004. Seasonal changes in poly amine content of vegetative and reproductive olive organs in relation to floral initiation, anthesis, and fruit development. Australian Journal of Agricultural Resources, 55: 1039- 1046.

Proietti, P. and Tombesi, A. 1996. Effects of gibberellic acid, asparagine and glutamine on flower bud induction in olive. Journal of Horticultural Sciences, 71(3): 383-388.

Rallo, L and G.C. Martin. 1991. The role of chilling in releasing olive bud from dormancy. Journal of American Society of Horticultural Sciences, 116: 10581062 .
Rallo, L. and Suarez, M.P. 1989. Seasonal distribution of dry matter within the olive fruit- bearing limb. Advances in Horticultural Science, 3: 55- 59.

Rallo, L., P. Torreno, A. Vargas and J. Alvarado. 1994. Dormancy and alternate bearing in olive. Acta Horticulture, 356: 127- 136.

Rapoport, H.F., Rallo, L. and Polito, V.S. 1990. Pit hardening in the olive. XIII Int. Hort. Congress, abstract $\mathrm{n}^{\circ} 2364$.

Rodrigues, M.A. and Correia, C.M. 2009. O ciclo bienal da oliveria. In M.A. Rodrigues e C.M. Correia (Eds.). Manual da Safra e contra Safra do Olival. Inst. Pol. Braganea. pp. 17- 20.

Rugini, E. and Pannelli, G. 1993. Preliminary results on increasing fruit set in olives (Olea europaea L.) by chemical and mechanical treatments. Acta Horticulture, 329: 209-210.

Ryan, D., Prenzler, P. D., Lavee, S., Antolovich, M. and Robards, K. 2003. Quantative changes in the phenolic content during Physiological Development of Olive (Olea europaea) cultivar Hardy's Mammoth. Journal of Agricultural Food Chemistry, 51: 25322538.

Ryuogo, K. 1988. Fruit Culture, Its Science and Art. Wiley, New York.

Saleh, M.S. and Mostafa, M. Q. 2008. Alternate bearing of the olive (Olea europaea L.) as related to endogenous hormonal content. Jordan Journal of Agricultural Sciences, 4(1): 12- 24.

Seyyednejad, M., H. Ebrahimzadeh and A. Talaie, 2001. Carbohydrate content in olive zard c.v. and alternate bearing pattern. International Sugar Journal, 103: 84-87.

Shulman, Y. and S. Lavee. 1976. Endogeneous cytokinins in maturing Manzanillo olive fruits. Plant Physiology, 57: 490- 492. 
Spann, T.M., R.H. Beede and T.M. DeJong. 2008. Seasonal carbohydrate storage and mobilization in bearing and nonbearing pistachio (Pistacia vera) trees. Tree Physiology, 28: 207-213.

Stan, K. and H. David, 2007. Producing Table Olives. Landlinks Press, 150 Oxford Street, Collingwood VIC 3066 Australia, pp: 346.

Stutte, G. and G.C. Martin. 1986. Effect of light intensity and carbohydrate reserves on flowering in olive. Journal of American Society of Horticultural Sciences, 111: 27-31.
Tapia, F., Ibacache, A. and Mora, F. 2006. Manejo del anerismo en el valle del Hausco. VII Jornadas Olivicolas- I encuentro Iberoamericano de Olivicultura, La Serena, Chile. 4, 5 y 6 de octubre. Instituto de Investigaciones Agropecuarias, La Serena, Chile.

Wusnsche, J.N., D.H. Greer, W.A. Laing and J.W. Palmer. 2005. Physiological and biochemical leaf and tree responses to crop load in apple. Tree Physiology, 25: 1253-1263.

\section{How to cite this article:}

Darpreet Kour, Parshant Bakshi, V.K. Wali, Nirmal Sharma, Arti Sharma and Mudasir Iqbal. 2018. Alternate Bearing in Olive - A Review. Int.J.Curr.Microbiol.App.Sci. 7(09): 2281-2297. doi: https://doi.org/10.20546/ijcmas.2018.709.283 